\title{
Mill Scales Blended Polymer Composites For Electrical Insulation Application
}

\author{
Jayasmita Beura ${ }^{1}$, Susanta Kumar Biswal ${ }^{1}$, Saurabh Kundu ${ }^{2}$ and Tapan Kumar Rout ${ }^{2,}$ \\ ${ }^{1}$ Department of Chemistry, Centurion University, Bhubaneswar, 751028, India \\ ${ }^{2}$ Research and Development Department, Tata Steel Ltd, 755026, India
}

\begin{abstract}
Standalone composite films were prepared using modified polyester as a binder and waste iron oxides (mill scales) collected from a steel plant as inorganic filler. The morphology, structure, composition, strength and electrical insulation properties of polymer-iron composites were studied using various analytical techniques such as X-ray diffraction (XRD), Scanning electron microscope (SEM), Atomic force microscopy (AFM), optical microscopy, Fourier transform infrared (FTIR) spectroscopy, X-ray fluorescence (XRF), Brunauer-Emmett-Teller (BET) test, particle size analysis and electrical insulation test. The mill scales collected from the hot strip rolling mill (HSM) have found to comprise three different phases such as wustite, magnetite and hematite. Composites prepared using mill scales were showing three times higher strength compared to the mother polymer film. Electrical insulation of these composites were found to increase in the range of $55-230 \mathrm{MV} / \mathrm{mm}$ with increasing iron oxide content from $0.0125 \mathrm{~g}$ to $0.25 \mathrm{~g}$ in $2.5 \mathrm{~g}$ polymer. These results show a potential research field on the mill scales based composites for various advanced applications in improving insulation behaviour of materials which can withstand at higher temperatures and electrical stresses.
\end{abstract}

Keywords: Mill scales, composites, iron oxides, electrical insulation, hardness, polymer film.

\section{INTRODUCTION}

Last few decades, all over the world the researchers are seriously involved in the design of composite materials comprising either micro-scaled or nanoscaled inorganic particles in power and high-voltage polymers engineering [1]. Particularly, the composites of micro and nanotechnologies offer new approaches towards improved insulation behaviour that operate at higher temperatures and electrical stresses. In the view of material performance and scale up manufacturing, basic research and technology development of new kind of advanced materials in the field of polymer composites have been gaining market share. Polymers are being used potentially as a component for formulating coatings, paints and engineered functionalities film. Sometimes polymer is inefficient to fulfil desired demand of applications in automotive, aerospace, electronics and medicals. Therefore composite concept has well pursued to obtain targeted properties by incorporating more than two components into a polymer matrix to reinforce the polymer film. Polyimide with clay has been explored for coatings and corrosion [2]; polyetherimide with silver oxide has been tried for corrosion prevention of mild steel [3]. Similarly, thermoplastic polyester polymers are most common for manufacturing bottles, liquid crystal displays holograms, filters, dielectric film for capacitors, film

*Address correspondence to this author at the Research and Development Department, Tata Steel Ltd, 755026, India; Tel: 91-8092088390;

E-mail: tkrout5@yahoo.com insulation for wire and insulating tapes etc [4]. Reinforcements are usually stronger than the mother polymer matrix that improves the mechanical properties of the polymer composite in addition to different functionalities. Polymer composite materials have been classified into two groups (a) fibre-reinforced polymer (FRP) and (b) particle-reinforced polymer (PRP) composites [5]. Fibre-reinforced polymer materials consist of fibres, which have high strength and modulus. Fibres can be bonded to the matrix, the interface that is boundary between the fibre and the matrix, which has different physical and chemical identities. Particle-reinforced polymer composites include ceramics, small particles which are used to increase the modulus and to decrease the ductility of the matrix. There are many inorganic particles/oxides are available for making PRP composites such as $\mathrm{ZnO}$, $\mathrm{ZrO}_{2}, \mathrm{Al}_{2} \mathrm{O}_{3}, \mathrm{SiO}_{2}$ etc. Most commonly used oxides in the form of nano size are $\mathrm{Al}_{2} \mathrm{O}_{3}, \mathrm{SiO}_{2}, \mathrm{TiO}_{2}, \mathrm{ZnO}$, $\mathrm{CeO}_{2}, \mathrm{MgO}$ and $\mathrm{CaCO}_{3}$ due to their inherent properties. For example $\mathrm{TiO}_{2}$ and $\mathrm{ZnO}$ nano-particles (NPs) are used as UV blocking agents; $\mathrm{Al}_{2} \mathrm{O}_{3}$ and $\mathrm{SiO}_{2}$ are used to improve abrasion and scratch resistance, and $\mathrm{CeO}_{2}$ and $\mathrm{MgO}$ NPs are used as anti-corrosion and high temperature oxidation resistant materials. In the power industry, inorganic filler (particularly aluminum nitride (AIN), boron nitride (BN), silica $\left(\mathrm{SiO}_{2}\right)$, alumina $\left(\mathrm{Al}_{2} \mathrm{O}_{3}\right)$, titanium oxide or titania $\left(\mathrm{TiO}_{2}\right)$, silicon carbide $(\mathrm{SiC})$ and zinc oxide ( $\mathrm{ZnO})$, etc. are usually incorporated to achieve electrical insulation, mechanical, and thermal properties [6]. There are very few articles on this functionality considering oxides 
from steel plant waste materials (mill scales). In this work we have explored mechanical and electrical insulation properties of the iron oxides based polymer composite with an objective to use mill scale waste materials for value addition. After preparing the composites, the samples were characterized by applying various advanced characterization techniques such as XRD, SEM, optical microscopy, FTIR, XRF, hardness, BET surface area and electrical insulation test.

\section{EXPERIMENTAL}

We collected mill scales from TSL India. The mill scale samples were collected from two different stages such as (a) furnace scale at furnace section $\left(1200{ }^{\circ} \mathrm{C}\right)$ Primary scale and (b) roughing scale from the descaling zone $\left(900{ }^{\circ} \mathrm{C}\right)$-Secondary scale. We used a vibrating cup mill (VCM) to prepare powder of mill scale samples of size $<200$ micron. The milling was carried out for five minutes in the vibrating cup mill, the vibrating cup mill breaks scales into fine powder. This powder was analysed to see the surface morphology, particle size, phases and surface area. Then polyester polymer and mill scale powder samples were taken for the preparation of mill scale based polymer composites. The mill scale with different percentage was added in $2.5 \mathrm{~g}$ of polyester, where concentrations of furnace scale and roughing scale were varying from $0.0125 \mathrm{~g}(0.5 \%), 0.075 \mathrm{~g}(3 \%)$, to $0.25 \mathrm{~g}(10 \%)$ into the polymer respectively. This mixed solution was casted onto the glass slide in order to make a thin film. This casted film was cured in room temperature overnight, and removed from the glass after 72 hours of curing by using water.

XRD patterns of the powder samples were studied by PANalyticalX'Pert Pro diffractometer equipped with CoKa radiation. The patterns were recorded in the $2 \theta$ range 5-95 at a scan speed of $0.017 \mathrm{~min}^{-1}$. The samples were used to generate micrograph using a Leica microscope and scanning electron microscopy (SEM). Specific surface area was determined by BET method (model: ASAP 2020, micrometrics, USA) by $\mathrm{N}_{2}$ adsorption-desorption technique. The particle sizes of powders were measured using Dynamic Light Scattering (DLS) and Nanoparticle Tracking Analysis (NTA) system. The composition of the collected furnace and roughing scales at powder stage are tested by XRF analyzer machine (X-ray fluorescence) model Rignku, ZSX Primus-II. The composites films were analyzed using Vickers micro-hardness to determine hardness of film supplied by LECO micro indentation hardness tester. The electrical insulation of the composites was measured using Megger MIT1025 insulation resistance tester. Fourier transforms infra-red (FTIR) spectra were used to measure interaction of particle with polymer chain by evaluating functional bonding in the range of $400-4000 \mathrm{~cm}^{-1}$ using spectrometer; Spectrum GX, PerkinElmer.

\section{RESULTS AND DISCUSSION}

X-ray diffraction (XRD) analysis was carried out to observe the crystalline nature, phase purity and interlayer spacing of polymer based iron oxide

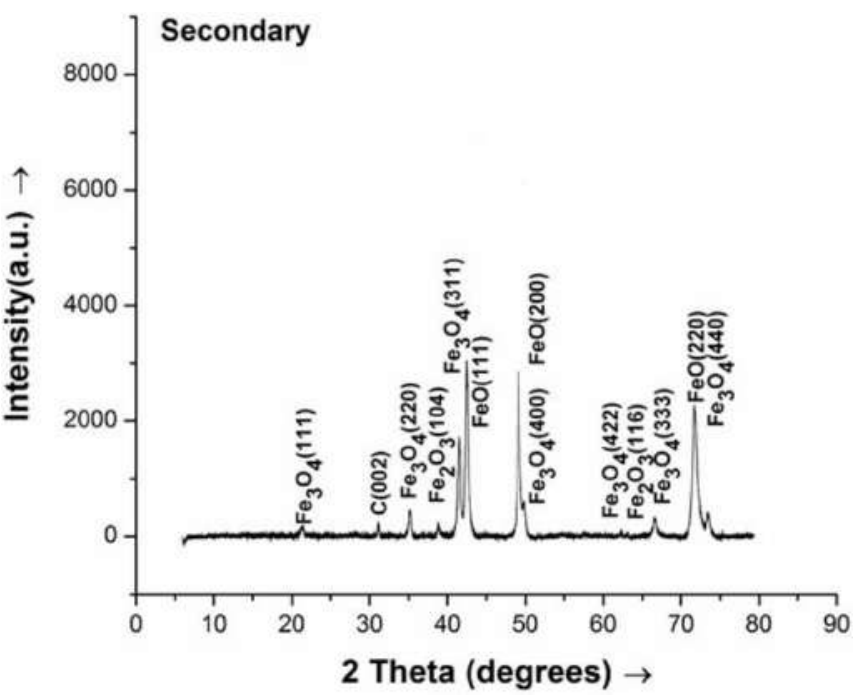

(b)

Figure 1: (a) and (b) show the typical XRD patterns of polymer + iron oxide (primary and secondary scale) prepared from polymer $2.5 \mathrm{~g}$ with $0.25 \mathrm{~g}$ iron oxide. 
composite samples (polymer with roughing and furnace scale). Phases and planes were identified by comparing the observed $d$-values with the $d$-values of standard powder diffraction data file, $\mathrm{Fe}_{3} \mathrm{O}_{4}$ : 01-0751609, FeO: 00-046-1312, $\mathrm{Fe}_{2} \mathrm{O}_{3}:$ 01-084-8104, C (graphite-2H): 00-025-0284 supplied in JCPDS-ICDD PDF-2 (2004). Figure $\mathbf{1} \mathbf{a}$ and $\mathbf{b}$ show the typical XRD patterns in $2 \theta$ range of $7.5^{\circ}-80^{\circ}$ of composites prepared from roughing and furnace scale samples showed composition of hematite, wustite and magnetite along with low content of carbon. The polymer composite prepared from furnace scale showed a typical strong $\mathrm{FeO}(200)$ peak at $2 \theta=49.41^{\circ}$ with an interlayer $d$ spacing of $0.214 \mathrm{~nm}$. It also shows major peak due to $\mathrm{Fe}_{3} \mathrm{O}_{4}$ and $\mathrm{Fe}_{2} \mathrm{O}_{3}$ and a minor peak due to $\mathrm{C}(002)$. Similarly the polymer composite prepared from roughing scale showed a peak due to $\mathrm{FeO}(200)$ peak at $2 \theta=49.45^{\circ}$ along with other peaks like $\mathrm{Fe}_{3} \mathrm{O}_{4}$ and $\mathrm{Fe}_{2} \mathrm{O}_{3}$ and $\mathrm{C}$ (002). It is marked that the intensity of $\mathrm{Fe}_{3} \mathrm{O}_{4}$ at $2 \theta=41.37^{\circ}$ is relatively decreased.

The most-important findings were that the XRD patterns conveyed the presence of the hematite layer and the wustite in the secondary scale and also the presence of relative amounts of the haematite and magnetite were detected in the primary scale. According to the hot rolling process parameters, the slab get heated up at reheating furnace at around 1200 ${ }^{0} \mathrm{C}$ and followed by roughing and finish rolling, the entire process takes 10 minutes to roll a steel sheet of around 2000 meters length. The flaky scale is thus removed from slab surface by hydraulic pressure at the exit point of furnace section of heated slab comprise wustite, magnetite and hematite. This matches with the results of phase we obtained from XRD pattern. Similarly, loose scale obtained after the exit point of several roughing stages comprises magnetite and hematite which is also matches with the results of XRD findings. At the roughing sections, the surface temperature of steel at around $900{ }^{\circ} \mathrm{C}$, the absence of wustite layer is due to the formation of magnetite to hematite at the expense of wustite at the magnetite and wustite interface. The effect of temperature plays a role for the generation of iron oxides during heating cycles. This was confirmed from the $\mathrm{Fe}-\mathrm{O}$ phase diagram shown in Figure 2 [7].

it is seen from the above phase diagram that the solubility of oxygen in wustite in the regions adjacent to the magnetite layer in the higher temperature range (e.g., $850-950{ }^{\circ} \mathrm{C}$ ) is much greater than that in the lower range (e.g., $650-750{ }^{\circ} \mathrm{C}$ ). In the hot rolling process, the steel sheets pass through several water

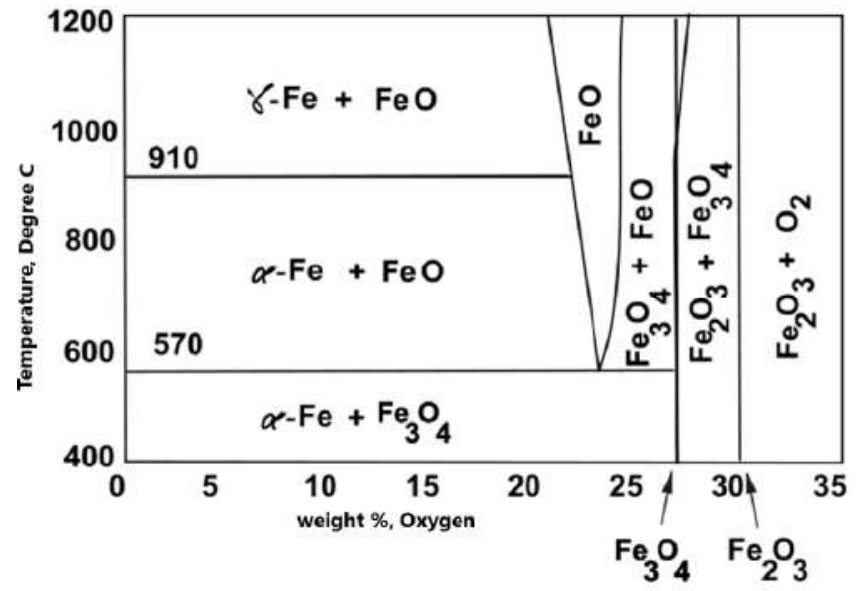

Figure 2: The Fe-O phase diagram (R. Y. Chen and W. Y. D. Yuen; Oxidation of Metals, Vol. 56, Nos. 1/2, 2001).

cooling stages in the roughing sections in order to achieve right mechanical properties without compromising the surface quality. As the cooling rate is required to be very rapid, proeutectoid magnetite may form in wustite in the regions near the wustitemagnetite interface, via the following reaction;

$$
F e_{1-x}=\left[\frac{x-y}{1-4 y}\right] F e_{3} O_{4}+[(1-4 x) /(1-4 y)] F e_{1-y} 0
$$

In ionic form at wustite-magnetite interface;

$$
(1-4 y) \mathrm{Fe}^{+2}+2 e^{-}+\mathrm{Fe}_{3} \mathrm{O}_{4} \rightarrow 4 \mathrm{Fe}_{1-y} \mathrm{O}
$$

Magnetite-hematite interface;

$$
\mathrm{Fe}^{+2}+2 e^{-}+4 \mathrm{Fe}_{2} \mathrm{O}_{3} \rightarrow 3 \mathrm{Fe}_{3} \mathrm{O}_{4} .
$$

When $x>y$ at above $900{ }^{\circ} \mathrm{C}$; the proeutectoid magnetite forms at the expense of the wustite layer, and as a result, a thick scale gets formed. Similarly, more magnetite forms at the hematite-magnetite interfaces at the expense of the existing hematite between $660-720{ }^{0} \mathrm{C}$ [8]. We know from the thermodynamics (Fe-O diagram) that at a certain temperature magnetite converted into hematite at the expense of wustite.

The compositional analysis obtained from XRF analysis for primary and secondary scales are presented in Table 1. We found that primary (furnace scale) is having comparatively lower ranges in concentration of hematite than the secondary (roughing scale). It was also detected that these scales are having other constituents like $\mathrm{NiO}, \mathrm{MoO}_{3}$ and $\mathrm{TiO}_{2}$ etc., These constituents are mostly migrating from the steel chemistry during the secondary rolling process 
Table 1: Composition Analysis of Scales from XRF Study

\begin{tabular}{|c|c|c|}
\hline Components & Primary Scale, \% & Secondary scale, $\%$ \\
\hline $\mathrm{Na}_{2} \mathrm{O}$ & 0.117 & 0.037 \\
\hline $\mathrm{Al}_{2} \mathrm{O}_{3}$ & 0.3674 & 0.1589 \\
\hline $\mathrm{SiO}_{2}$ & 1.5054 & 0.5552 \\
\hline $\mathbf{P}_{2} \mathbf{O}_{5}$ & 0.055 & 0.026 \\
\hline $\mathrm{SO}_{3}$ & 0.0729 & 0.0335 \\
\hline $\mathrm{K}_{2} \mathrm{O}$ & 0.0429 & 0.0103 \\
\hline $\mathrm{CaO}$ & 0.4398 & 0.2979 \\
\hline $\mathrm{TiO}_{2}$ & 0.0242 & - \\
\hline $\mathrm{Cr}_{2} \mathrm{O}_{3}$ & 0.0259 & 0.0195 \\
\hline MnO & 0.6846 & 0.6370 \\
\hline $\mathrm{NiO}$ & 0.0168 & - \\
\hline $\mathrm{Nb}_{2} \mathrm{O}_{5}$ & 0.0042 & 0.0035 \\
\hline $\mathrm{MoO}_{3}$ & 0.0088 & \\
\hline Total iron oxide $\left(\mathrm{FeO}+\mathrm{Fe}_{3} \mathrm{O}_{4}+\mathrm{Fe}_{2} \mathrm{O}_{3}\right)$ & 96.3921 & 98.1427 \\
\hline
\end{tabular}

because $\mathrm{Ni}$, Mo and $\mathrm{Ti}$ gets oxidized as the oxygen concentration increasing over the time. Therefore it is confirmed that primary scale is having more wustite percentage as compared to the secondary scale.

To investigate the effect of particle size in composites, the particle size of iron oxides were determined. We evaluated particle size of the iron oxides powder using water as a carrier solvent where $0.0069 \mathrm{~g}$ of powder were dispersed in water using hexa metaphosphate dispersant to avoid agglomeration at lower stirring condition during measurement. We observed that $90 \%$ particles of size below $46-53$ micro meter in the powder made from primary scale and secondary scale using swing grinding machine which is presented in the Figure 3 . The surface area of the samples was found to be in between $1.75 \mathrm{~m}^{2} / \mathrm{g}$ to 1.82 $\mathrm{m}^{2} / \mathrm{gm}$. From the above observations, it can be concluded that at the same conditions of grinding of both scales, the particle size and surface area were almost the same.

We made polymer composites using both primary and secondary scales which are having almost three different iron oxides at varying percentages. After mixing these scales into a mother polymer solution, we could use optical and FTIR techniques to know their interactions.

The FTIR spectra of two typical polymer composites with primary and secondary scale $(0.25 \mathrm{~g})$ were recorded in the mid IR region. The spectra is given in Figure 4 and each peak was identified following to the literature and presented in the Table 2. From the Tabe
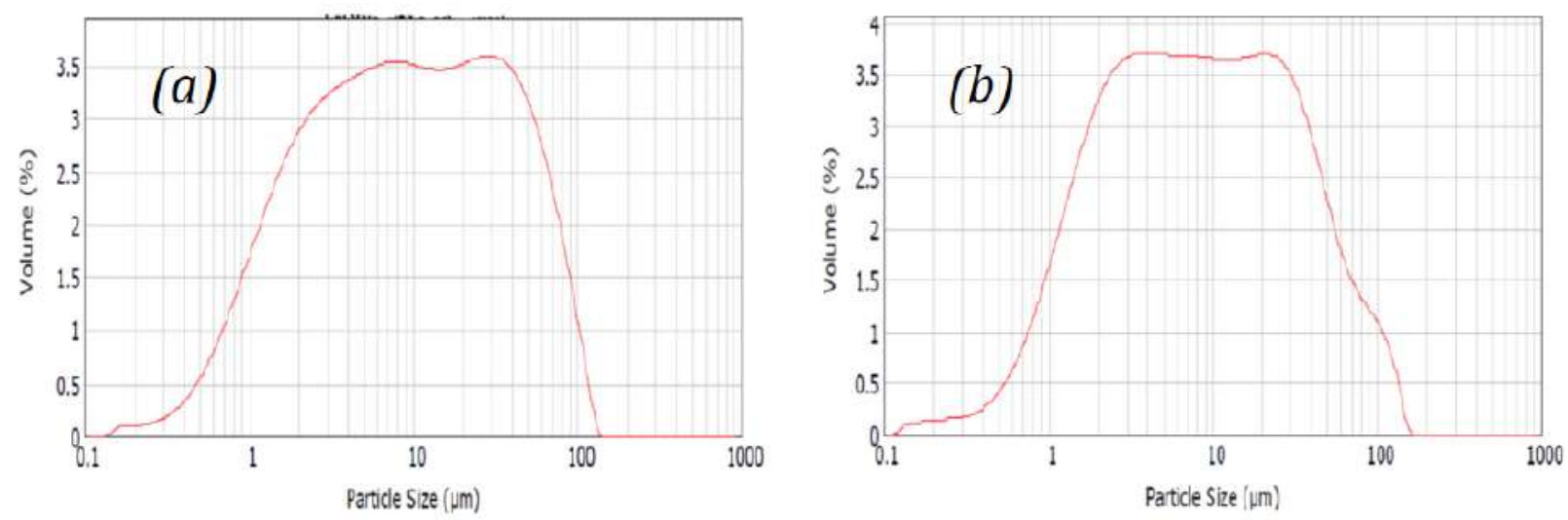

Figure 3: Particle size analysis of (a) Primary and (b) secondary mill scales. 


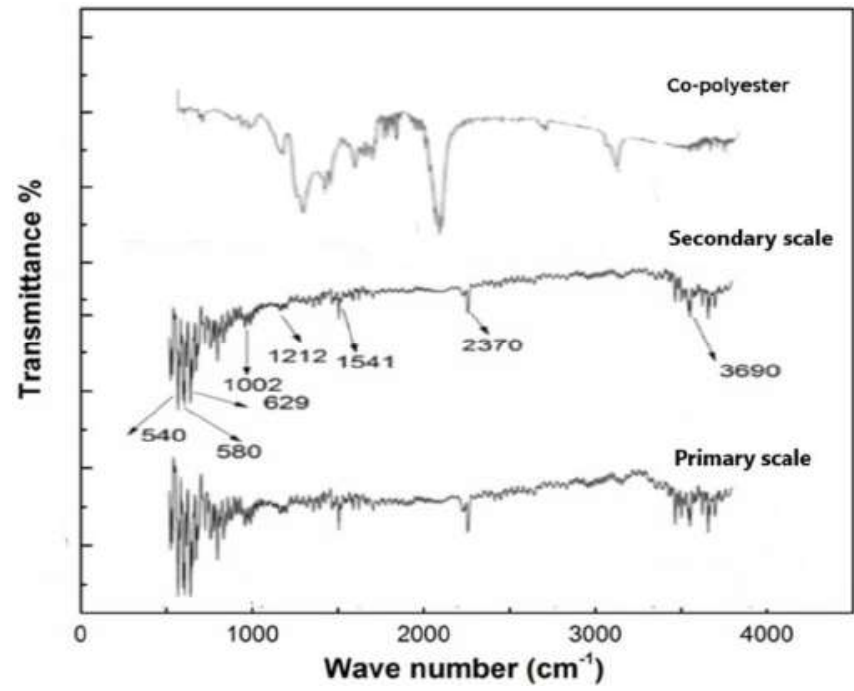

Figure 4: FTIR spectra of polymer with roughing and furnace scale iron oxide composites.

2, we found that polymer composites are having all three oxidation form of iron as in the stretching mode. The presence of such peaks indicate the formation of a bond between $\mathrm{Fe}(+1,+2,+3)$ with $-\mathrm{COO}^{-}$. The results can be corroborated to our XRD and XRF results where all three oxidation form of iron were detected in primary (furnace) and secondary (roughing) scales. This ionic interaction between iron oxide surface and the functional groups of polymer chain was evdenced from the FTIR analyis and homogeneious distribution of particles were deteted using optical microscope. It was found from the FTIR study that the mother polymer and the composites are showing different characteristic peaks at different wavelengths. The characteristic peaks of the $\mathrm{FeO}$ group are showed in the region of 540 and $571 \mathrm{~cm}^{-1}$ indicating that the presence of iron oxide in the polymer matrix. The band in $1170 \mathrm{~cm}^{-1}$ is a characteristic one for the group $\mathrm{C}-\mathrm{O}-\mathrm{C}$, present in the polymer indicating a polyester class of polymer. The band at $1724 \mathrm{~cm}^{-1}$ in the mother polymer is related to the stretching of the carbonyl group of the carboxylic acid. This band is shifted to lower energy wavelength of $1541 \mathrm{~cm}^{-1}$ indicating that the carboxylate group of the polymer is making chemical bond with the structure of iron oxide $[8,9]$. The bands at $3400-3600 \mathrm{~cm}^{-1}$ assigned to the vibration of $\mathrm{OH}$ group linked on the surface of iron oxide, hence iron oxide is hydrophilic in nature, and highly compatible to the organic components. This is information is indicating that the interaction is being established between the polymer and the particles of the Iron oxide [10-14].

Microscopic analysis was evidenced (Figure 5) that the furnace scale and roughing scale powder at $0.25 \mathrm{~g}$ $(10 \%)$ shows almost homogenous distribution of powder in the film.

So, it can be derived from the microscopic observation that a critical concentration is required to achieve a homogeneous composite. After, optimizing iron oxide concentration in the mother polymer solution we tried to understand its surface homogeneity by using atomic force microscope (AFM) [15,16] and mechanical strength by measuring hardness value [17]. AFM is a technique used to map $3 \mathrm{D}$ images of surface roughness of a sample surface of interest. The noncontact interaction between the tip of cantilever and the sample surface give rise to deflections which are used to generate a map of the surface topography. Surface imaging of the samples in $\mathrm{X}, \mathrm{Y}$ and Z-directions were 299, 298 and $8.048 \mu \mathrm{m}$, respectively. The AFM resolution along the $X, Y$ and $Z$-axes was $<5 \mathrm{~nm}$. We recorded the scanning images using AFM without polishing the samples so as to retain their original surface morphology. We observed that the primary scale based composite showing surface roughness of $1.04 \mu \mathrm{m}$ with fine-grained morphology leads higher hardness. The coarser grains images with surface

Table 2: FTIR Peak Identification in Polymer with Roughing and Furnace Scale Iron Oxide Composites

\begin{tabular}{|c|c|}
\hline Wave numbers $\left(\mathbf{c m}^{-1}\right)$ & Peak assignment \\
\hline \hline 540 & $\mathrm{Fe}_{2} \mathrm{O}_{3}$ Stretching mode \\
\hline 580 & $\mathrm{Fe}_{3} \mathrm{O}_{4}$ Stretching mode \\
\hline 670 & $\mathrm{FeO}(\mathrm{OH})$ Stretching mode \\
\hline 1002 & $\mathrm{C}-\mathrm{O}$ \\
\hline 1212 & Asymmetric vibration of COO- \\
\hline 1541 & Symmetric COO-group of vibrations \\
\hline 2370 & polyatomic Cn-H-O entitles with C bonded to two or three $\mathrm{H}$ \\
\hline 3690 & OH stretching mode \\
\hline
\end{tabular}



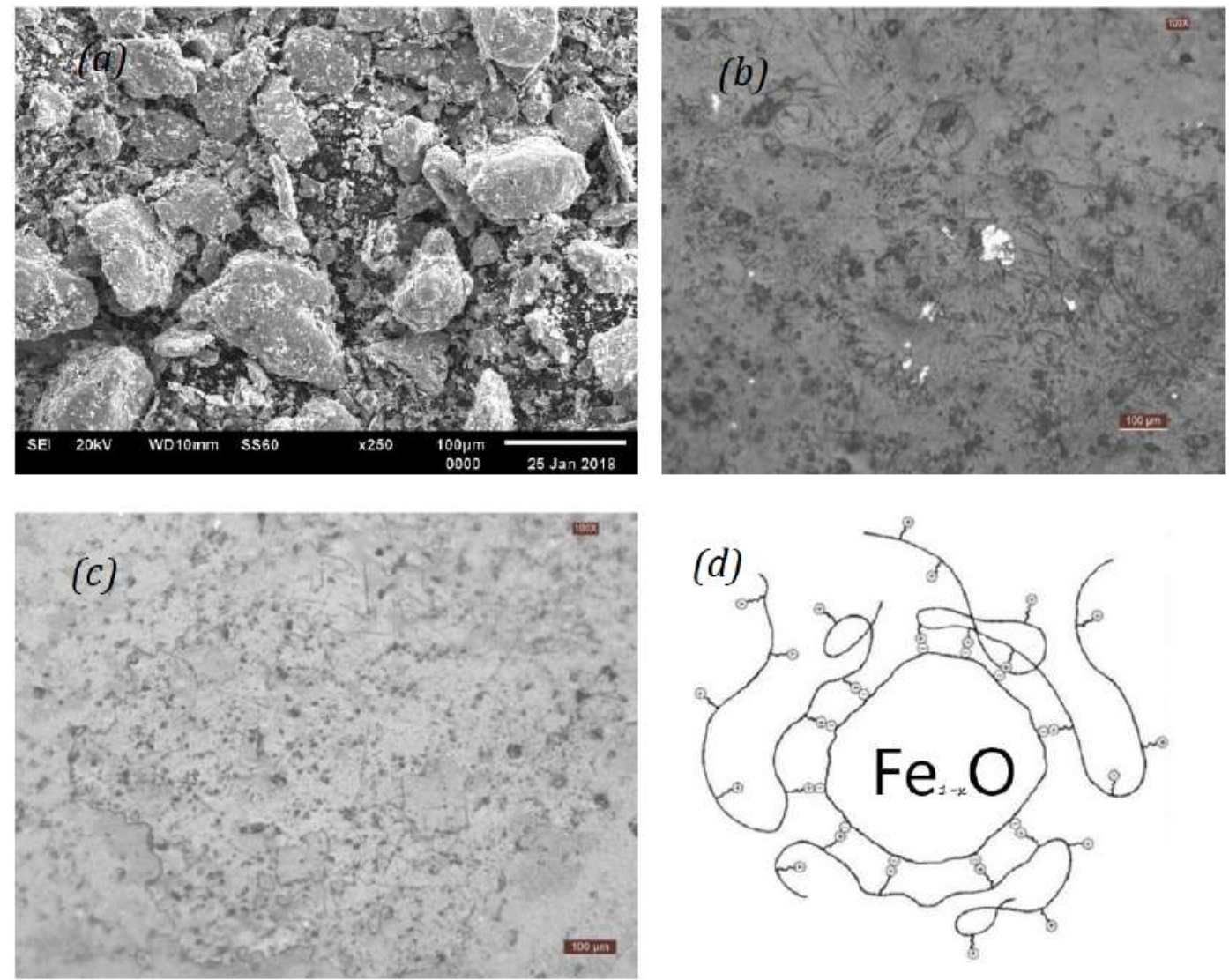

Figure 5: Surface images of (a) iron oxides, (b) polymer with $0.25 \%$ iron oxides of primary scale, (c) polymer with $0.25 \%$ iron oxides of secondary scale and (d) scehamatic mechanism of interaction of polymer with iron oxide.
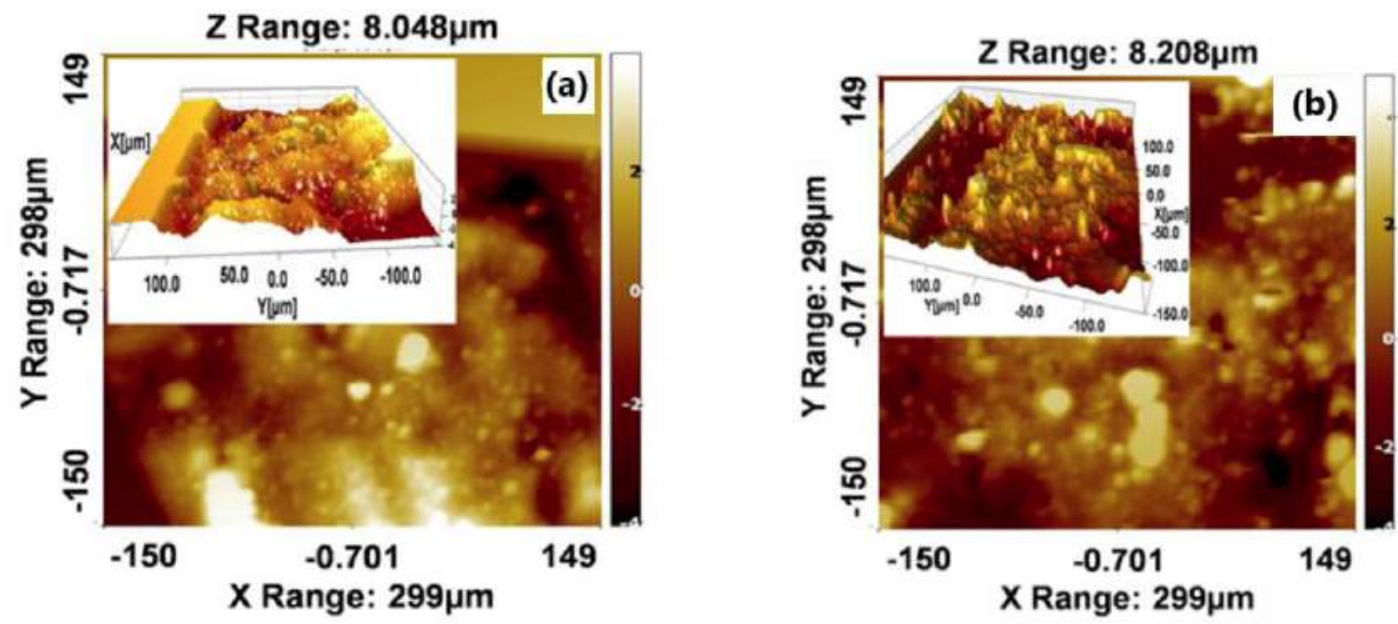

Figure 6: AFM Surface topography images of (a) 0.25 wt $\%$ Primary scale based composite, (b) 0.25 wt $\%$ secondary scale composite.

roughness $1.48 \mu \mathrm{m}$ are found from secondary scale based composites leads to lower hardness of the films.

The HV number is then determined by the ratio $F / A$, where $F$ is the force applied to the diamond in gramsforce and $A$ is the surface area of the resulting indentation in square millimeters. $A$ can be determined by the formula [17].

$$
A=\frac{d^{2}}{2 \sin \left(136^{\circ} / 2\right)}
$$

which can be approximated by evaluating the sine term to give,

$$
A=\frac{d^{2}}{1.8544},
$$


where $d$ is the average length of the diagonal left by the indenter in millimeters. Hence ${ }^{1}$

$$
H V=\frac{F}{A} \approx \frac{1.8544}{d^{2}} \quad\left[\mathrm{kgf} / \mathrm{mm}^{2}\right]
$$

The corresponding units of HV are then kilogramsforce per square millimeter $\left(\mathrm{kgf} / \mathrm{mm}^{2}\right)$. To calculate Vickers hardness number using SI units, it is needed to convert the force applied from newtons to kilogramforce by dividing by 9.8 (standard gravity). This leads to the following equation:

$$
H V \approx 0.1891 \frac{F}{d^{2}} \quad\left[\mathrm{kgf} / \mathrm{mm}^{2}\right],
$$

If $\mathrm{HV}$ is expressed in $\mathrm{kg} / \mathrm{mm}^{2}$ then the yield strength (in $\mathrm{MPa}$ ) of the material can be approximated as $\sigma_{u} \approx$ $\mathrm{HV} \times \mathrm{C} \approx \mathrm{HV} / 0.3$, where $c$ is a constant determined by geometrical factors usually ranging between 2 and 4 .

We could plot a diagram mentioning measured hardness on applied loads as shown in Figure 7. The results of hardness in $\mathrm{HV}$ is converted into strength in megapascals $(\mathrm{mPa})$ for composites. Hardness values are found rising in case of composites as compared to a mother polymer. This increased may be due to interaction of iron oxide particles with the polymer matrix due to particle reinforcement. A schematic picture of particle an polymer interaction is given in Figure $\mathbf{5 d}$ where polymer is found to hold the particles strongly with a chemical force which is evident by FTIR analysis therefore, the strength of the composites is increasing almost four times compared to mother polymer as shown in Figure 6.

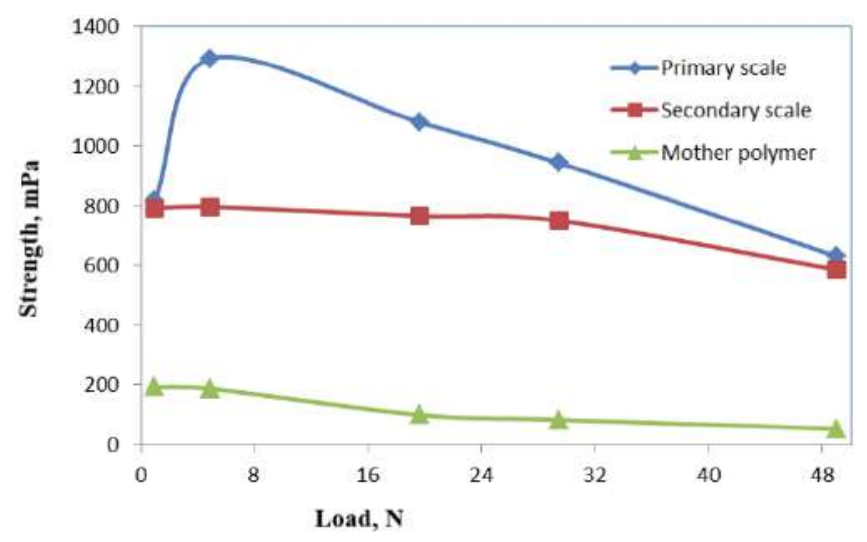

Figure 7: Polymer strength vs applied load.

This indicates that the polymer composites thus made was found suitable for the requirements of flexible components with high hardness. This flexible polymer composite with comparative high strength film is of high demand in the electronics industry because of an unique requirement. This developed composite is suitable for dielectric application as because of high dielectric strength of the polymer-iron oxide composites which was evaluated using Megger apparatus and the data presented in Table 3.

Table 3: Determination of Dielectric Strength of Polymer-Iron Composite

\begin{tabular}{|c|c|c|}
\hline \multirow{2}{*}{$\begin{array}{c}\text { Sample ID \% } \\
\text { of iron oxide }\end{array}$} & \multicolumn{2}{|c|}{$\begin{array}{r}\text { Dielectric strength for polymer-iron oxide } \\
\text { composite (megavolt/mm) }\end{array}$} \\
\cline { 2 - 3 } & Primary scale & Secondary scale scale \\
\hline \hline 0.0125 & 60 & 55 \\
\hline 0.075 & 95 & 70 \\
\hline 0.25 & 220 & 230 \\
\hline
\end{tabular}

We found that dielectric strength of polymer-iron oxide composite increases around $200 \mathrm{MV} / \mathrm{mm}$ as the content of iron oxide in the composite increases. The reason of sharp changes of strength may be attributed to the non-orientation of dipole moment of iron oxide atoms in the polymer composites against the applied electric field [18,19 \&20]. Hence the new composites offer a new approach towards improved insulation behaviour that operates at higher temperatures and electrical stress.

\section{CONCLUSIONS}

The roughing and furnace mill scales collected from the hot rolling mill have found to contain of wustite, magnetite and hematite as confirmed from XRD and XRF analysis. Mill scale powders were successfully prepared using swing vibrating machine. The observed particle size in the range of 56 micron with surface area of $1.87 \mathrm{~m}^{2} / \mathrm{g}$ is found suitable for making a polymer composite. The polymer composite based on furnace scale and roughing scale has no much difference in hardness and dielectric strength. The hardness of polymer-iron oxide was found to increase 4-5 times higher than that of mother polymer. It was interestingly observed that the dielectric strength increases up to around $200 \mathrm{MV} / \mathrm{mm}$ by increasing iron oxide content from 0.0125 to $0.25 \mathrm{~g}$. The optimised iron oxide concentration of 0.25 in the polymer is found suitable for making standalone film as the surface looks uniform and away from agglomeration of particles. We found that these polymer composites can be used for flexible dielectric film with certain hardness for electrical applications as the dielectric values in the range of 55$230 \mathrm{MV} / \mathrm{mm}$ which is very high as compared to any conventional composite film. 


\section{ACKNOWLEDGEMENTS}

Authors are thankful to the Centurion University, Bhubaneswar for giving permission to publish this article. Sincere thanks to IMMT, Bhubaneswar for providing facilities to carry out characterisations. We are also thankful to Tata Steel Ltd for providing samples to carry out experiments.

\section{REFERENCES}

[1] No,tingher IPPV, Schlögl S, Sumereder C, Muhr M. Properties of Polymer Composites Used in High-Voltage Applications. Polymers 2016; 8: 173.

https://doi.org/10.3390/polym8050173

[2] Deng J, Lee MMK, Wan B, Amato G. Fibre reinforced polymer composites for structural applicaions in construction. Internal Journal of Polymer Science 2017; article ID 9218529, 1.

[3] Jenaa KK, Rajua KVSN, Narayana R, Rout TK. Sodium montmorillonite clay loaded novel organic-inorganic hybrid composites: Synthesis and characterization. Polym Int 2012; 61: 1101-1106.

[4] Routa TK, Gaikwadba AV. In-situ generation and application of nanocomposites on steel surfacefor anti-corrosion coating. Tata Progress in Organic Coatings 2015; 79: 98-105. https://doi.org/10.1016/j.porgcoat.2014.11.006

[5] Polymer Nanocomposites in High Voltage Electrical Insulation Perspective: A Review; Malaysian Polymer Journal 2011; 6(1): 58-69.

[6] Chen RY, Yuen WYD. Review of the High-Temperature Oxidation of Iron and Carbon Steels in Air or Oxygen. Oxidation of Metals 2003; 59(5/6): 2003. https://doi.org/10.1023/A:1023685905159

[7] Chen RY, Yuen WYD. Oxide-Scale Structures Formed on Commercial Hot-Rolled Steel Strip and Their Formation Mechanisms. Oxidation of Metals 2001; 56(1/2). https://doi.org/10.1023/A:1010395419981

[8] Garza-Montes-de-Oca NF, Ramı'rez-Ramı'rez JH, AlvarezElcoro I, Rainforth WM, Cola's R. Oxide Structures Formed During the High Temperature Oxidation of Hot Mill Work Rolls. Oxide Met 2013; 80: 191-203; DOI 10.1007/s11085013-9404

[9] Wikipedia-the Free Encyclopaedia. Available online:https://en.wikipedia.org/wiki/Nanocomposite (accessed on 9 December 2015).

[10] Goulart SAS, Oliveira TA, Teixeira A, Mulinari DR, Mulinari DR. Mechanical Behaviour of Polypropylene Reinforced
Palm Fibers Composites. Procedia Engineering 2011; 10: 2038-2043.

https://doi.org/10.1016/j.proeng.2011.04.337

[11] Iron Oxide Nanoparticles Coated with Polymer Derived from Epoxidized Oleic Acid and Cis-1,2-Cyclohexanedicarboxylic Anhydride: Synthesis and Characterization, Journal of Material Science \& Engineering 2016; 5(3).

https://doi.org/10.4172/2169-0022.1000247

[12] Nicolau A, Mariath RM, Martini EA, Martini DS, Samios D. The polymerization products of epoxidized oleic acid and epoxidized methyl oleate with cis-1,2 cyclohexanedicarboxylic anhydride and triethylamine as the initiator: Chemical structures, thermal and electrical properties. Materials Science and Engineering: C, 2010; 30(7): 951-962.

https://doi.org/10.1016/j.msec.2010.04.014

[13] Superparamagnetic Iron Oxide Nanoparticles as MRI contrast agents for Non-invasive Stem Cell Labeling and Tracking Theranostics 2013; 3(8): 595-615. https://doi.org/10.7150/thno.5366

[14] Agarwal T, Gupta KA, Alam S, Zaidi MGH. Fabrication and Characterization of Iron Oxide Filled Polyvinyl Pyrrolidone Nanocomposites. International Journal of Composite Materials 2012; 2(3): 17-21. https://doi.org/10.5923/j.cmaterials.20120203.01

[15] Barshilia HC, Rajam KS. Indian Academy of Sciences. Bull Mater Sci 2004; 27(1): 35-41. https://doi.org/10.1007/BF02708482

[16] Schiffmann K. Microwear experiments on metal-containing amorphous hydrocarbon hard coatings by AFM: Wear mechanisms and models for the load and time dependence. Wear 1998; 216: 2734. https://doi.org/10.1016/S0043-1648(97)00292-5

[17] Mares V, Kraus M, Podeprelova A. The Effect of Applied Load on Hardness of Steels. Materials Science Forum 201605-31 ISSN: 1662-9752; 891: 83-88

[18] Tanaka T, Montanari GC, Mülhaupt R. Polymer nanocomposites as dielectrics and electrical insulationPerspectives for processing technologies, material characterization and future applications. IEEE Trans Dielectr Electr Insul 2004; 11: 763-784. https://doi.org/10.1109/TDEI.2004.1349782

[19] Shah KS, Jain RC, Shrinet V, Singh AK, Bharambe DP. High density polyethylene (HDPE) clay nanocomposite for dielectric applications. IEEE Transactions on Dielectrics and Electrical Insulation 2009; 16(3): 853-861. https://doi.org/10.1109/TDEl.2009.5128526

[20] Joshi K, Joshi S. Polymeric based electric insulation coatings. WO2011061762A22009-11-23. 